\title{
Correspondence
}

\section{Physical activity and asthma in children: a long way to go in China}

\section{To the editor}

A sthma in children remains an important health problem in China. Although it is widely accepted that strenuous physical activity may trigger bronchial constriction in asthmatic children, appropriate exercise has been proven beneficial to asthmatic children. ${ }^{[1]}$ Unfortunately, in China, asthmatic children and their parents, teachers, and doctors are rarely aware of these benefits and still hold negative views of exercise. In a recent issue of the World Journal of Pediatrics, Cheng et $\mathrm{al}^{[2]}$ reported a significantly lower participation in physical activity among asthmatic children than healthy controls, which provided useful information for understanding the exercise status of asthmatic children in China. They also highlighted the need for updating the attitude, knowledge and practice of children, parents, teachers and doctors in physical activity/exercise and asthma in China.

I would like to make some methodological comments on their study. First, all asthmatic children in this study were recruited from a single hospital. It would be preferable if the authors had described how representative the participants in this study were for all asthmatic children in this city. Thus, the generalization of their results to all asthmatic children in Chongqing would be clear. Second, the authors used two indicators to measure the frequency (days per week) and intensity (minutes per day) of physical activity. More information would be provided if additional integrated indicators such as "minutes per week" calculated by multiplication of the two indicators had been used as supplementary. Third, the study was conducted in spring and early summer (February to June). Evidently the authors did not take into account the seasonal variations in physical activity, especially the avoidance of exercise in relation to seasonal asthma. Collecting information on children's physical activities in different seasons is suggested for future studies.

In addition, Cheng and colleagues suggested appropriate exercise for asthmatic children. ${ }^{[2]}$ However, we currently lack well-developed and evidence-based recommendations of exercise for asthmatic children in China. More analytical and, preferably, experimental studies are needed to ascertain appropriate frequency, intensity, and even types of exercise for asthmatic children.
Chao Sun, MSc

Faculty of Wushu, Chengdu Sport University No. 2, Tiyuan Road, Chengdu 610041, China

Email: youpingli@163.com

\section{References}

1 Willimas B, Powell A, Hoskins G, Neville R. Exploring and explaining low participation in physical activity among children and young people with asthma: a review. BMC Fam Pract 2008;9:40.

2 Cheng BL, Huang Y, Shu C, Lou XL, Fu Z, Zhao J. A crosssectional survey of participation of asthmatic children in physical activity. World J Pediatr 2010;6:238-243.

doi: 10.1007/s12519-011-0271-y

\section{Author reply}

7 o the questions raised by Dr Sun, our replies are as follows.

The asthma outpatient department of our hospital is the only Children Asthma Center in Chongqing city established 18 years ago. The center serves a population of around 25000 children from rural and urban areas of Chongqing city. Thus the participants in our study were representative of asthma children in Chongqing city.

Appropriate quantitative indicators are very important for the measurement of the frequency and intensity of physical activities. According to the latest reports and the consensus of American College of Sports Medicine, ${ }^{[1-3]}$ two indicators "days per week" and "minutes per day" were chosen in our study ${ }^{[4]}$ If only "minutes per week" was used as an index in the study, it was hard to show the frequence and the time distribution of exercise in a week. It may be more accurate to add "minutes per week" as another indicator to the indicators "days per week" and "minutes per day" as suggested by Dr. Sun.

The asthmatic children were enrolled in the study from February to June 2009, and they were followed up for 4 months. This paper only reported the preliminary results of a muti-center study. This study was a subtopic of a 115 major multi-center study program supported by the National Commission of Science and Technology of China. There are many issues concerning exercise prescription in asthmatic children being and to be investigated in China. 